\title{
Extração de ácido clorogênico de farelo de girassol desengordurado
}

\author{
Extraction of chlorogenic acid from deffated sunflower meal
}

\section{Patricia Mattos da Rosa ${ }^{\mathrm{I}}$ Rosemar Antoniassi ${ }^{\mathrm{II}}$ Elisabeth Borges Gonçalves ${ }^{\mathrm{II}}$ Humberto Ribeiro Bizzo ${ }^{\text {II }}$ Antonio Jorge Ribeiro da Silva ${ }^{\text {III }}$}

\section{RESUMO}

\begin{abstract}
A cultura de girassol (Helianthus annuus L.) vem se consolidando no Brasil, pois se adapta a diversas regiões do país e apresenta características interessantes tanto do ponto de vista agronômico, quanto em relação à composição do óleo e à qualidade de sua proteína. O farelo desengordurado de girassol tem sido utilizado para ração, mas seu escurecimento limita o uso para consumo humano. O farelo contém ácido clorogênico, um potente antioxidante, que quando oxidado pela polifenoloxidase gera compostos que causam o escurecimento e reduzem a qualidade nutricional da proteína. Neste trabalho, foram obtidos extratos de ácido clorogênico, a partir do farelo desengordurado de girassol, utilizando-se metanol ou etanol como solvente, nas temperaturas de 25, 40 e $60^{\circ} \mathrm{C}$ e tempos de contato de 30 e 60 minutos, constituindo um experimento a três critérios de classificação. Houve diferença significativa entre solventes, tempo e temperaturas $(P<0,05)$. A maior eficiência de remoção de ácido clorogênico foi de $40 \%$, quando o metanol foi utilizado. Os extratos de ácido clorogênico obtidos têm potencial de uso como antioxidante.
\end{abstract}

Palavras-chave: Helianthus annuus L., ácido clorogênico, girassol, CLAE, eficiência de extração.

\section{ABSTRACT}

The culture of sunflower (Helianthus annuus $L$.) has been consolidated in different regions of Brazil, and presents interesting characteristics on agronomic aspects, oil composition and protein quality. The defatted sunflower meal has been used to feed, but browning limits its use for human consumption. Sunflower meal contains chlorogenic acid, a potent antioxidant, which in turn is oxidized by polyphenol oxidase, producing compounds that darken the meal and reduce the nutritional quality of protein. In this research chlorogenic acid extracts were obtained from defatted sunflower meal, using methanol or ethanol as solvent, at temperatures of 25, 40 and $60^{\circ} \mathrm{C}$ and contact times of 30 and 60 minutes in a three classification criteria experiments. There were significant differences between solvent, time and temperature $(P<0.05)$. The highest removal efficiency of chlorogenic acid was of $40 \%$, when methanol was used. Chlorogenic acid extracts obtained have potential for use as antioxidant.

Key words: Helianthus annuus L., chlorogenic acid, sunflower, HPLC, extraction efficiency.

\section{INTRODUÇÃO}

O girassol (Helianthus annuus L., família Asteraceae) é uma planta nativa do México e atualmente é considerada como uma das melhores opções entre as oleaginosas, em virtude da qualidade de óleo, rico em ácidos graxos polinsaturados e em vitamina $\mathrm{E}$, além da alta digestibilidade da sua proteína (BERNARDINI, 1983; GROMPONE, 2005).

Entre os fatores decisivos para o fortalecimento do cultivo do girassol no Brasil está a demanda cada vez maior por óleo comestível e biocombustíveis, além da possibilidade do uso do farelo na alimentação animal (FERRARI, 2004).

O farelo de girassol é um subproduto do processo de extração industrial de óleos da semente

'Departamento de Tecnologia de Alimentos, Universidade Federal Rural do Rio de Janeiro (UFRRJ), BR 465, km 7, 23890-000, Seropédica, RJ, Brasil. E-mail: patriciamrosa@terra.com.br. Autor para correspondência.

"Embrapa Agroindústria de Alimentos, Rio de Janeiro, RJ, Brasil.

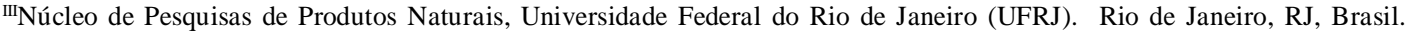


(com ou sem casca), utilizado como componente de ração animal. Apesar do alto conteúdo de proteína, apresenta também alto conteúdo de fibras, que reduz a energia digestível, e baixo teor de lisina (FURLAN et al., 2001).

Atualmente, o termo ácido clorogênico (ACG) é usado para designar uma família de ésteres formados pela esterificação de um ou mais derivados do ácido trans-cinâmico com o ácido quínico (DE MARIA \& MOREIRA, 2004). A semente de girassol apresenta quantidades variáveis de ACG, ácido caféico e isômeros do ácido di-cafeoil-quínico que estão concentrados na amêndoa (PEDROSA et al., 2000). A presença de ACG no farelo está associada ao desenvolvimento de cor verde escura e marrom sob processamento aquoso ou condições alcalinas. A reação de escurecimento ocorre pela ação de polifenoloxidase que oxida o ACG e as substâncias resultantes reagem com a proteína, reduzindo a quantidade de aminoácidos essenciais, a digestibilidade e a qualidade nutricional, além de alterar a funcionalidade e a aceitabilidade das proteínas (PEDROSA et al., 2000; GONZALEZ-PEREZet al., 2002; SEN \& BHATTACHARYYA, 2000; MARTINEZ \& DUVNJAK, 2006).

Muitos métodos têm sido propostos para remoção dos compostos fenólicos de farelo desengordurado de girassol, como a extração com solventes orgânicos e água, soluções ácidas, salinas, filtração com membranas ou combinação desses processos. Apesar de os processos de extração com solventes orgânicos e água serem eficientes na remoção de ACG, ocorrem alterações na qualidade protéica devido à desnaturação, redução de solubilidade e perdas na recuperação das proteínas (GONZALEZ-PEREZ et al., 2002). Outros processos para remoção de ACG incluem radiação gama associada a tratamentos com calor seco e úmido (FARAG, 1999) e o uso de enzimas (DE LEONARDIS et al., 2006; MARTINEZ \& DUVNJAK, 2006). Extratos de ACG obtidos com metanol a partir de farelo de girassol foram avaliados quanto à capacidade antioxidante com bons resultados, mas inferiores àqueles obtidos com antioxidantes sintéticos (ALLAM \& BASSIUNY, 2002).

Neste trabalho, a eficiência de remoção de ACG de farelo de girassol foi avaliada na extração com metanol ou etanol anidros, nas temperaturas de 25, 40 e $60^{\circ} \mathrm{C}$ e tempos de 30 e 60 minutos de contato.

\section{MATERIAL E MÉTODOS}

Obtenção das sementes de girassol

Sementes de girassol da variedade EMBRAPAF2 BRS 191 foram fornecidas pelo Centro
Nacional de Pesquisa de Soja / Embrapa Soja, Londrina, PR. As sementes de girassol com casca foram secas em estufa sem aeração a $100^{\circ} \mathrm{C}$ por 60 minutos, segundo o método proposto por BERNARDINI (1983), trituradas em moinho de rolos industrial Tecmolin (Moinho Indústria e Comércio Tecmolin Ltda) modelo PGI/EB e separação de cascas em agitador de peneiras oscilatórias Tyler modelo RX-29-10, tipo Rotap, serie 10948, com peneiras de 12, 16, 24, 35, 40 e 48mesh.

Obtenção do farelo desengordurado

As sementes sem casca foram trituradas e condicionadas em cartuchos de celulose para extração do óleo com éter de petróleo $\left(30-60^{\circ} \mathrm{C}\right)$, em aparelho de Soxhlet, por 16 horas para obtenção do farelo desengordurado (AOCS, 2009).

Extração e análise dos ácidos polifenólicos

As análises de ACG e ácido caféico foram realizadas nas amostras de farelo desengordurado e no extrato. Para análise do teor inicial dos ácidos polifenólicos no farelo desengordurado, foi realizada extração utilizando-se $50 \mathrm{mg}$ de farelo para $70 \mathrm{~mL}$ de solução aquosa de metanol a 70\%, com agitação por 120 minutos, à temperatura ambiente. Após filtração, completou-se o volume em balão volumétrico de $100 \mathrm{~mL}$ com a mesma solução da extração.

Para obtenção do extrato, foram utilizados como solventes o metanol anidro ou etanol 99\% PA, para extração dos compostos fenólicos nas temperaturas de 25,40 e $60^{\circ} \mathrm{C}$, com tempos de contato 30 e 60 minutos. Assim, foi utilizado um experimento a três critérios de classificação. Os ensaios foram realizados em duplicata.

A proporção entre farelo desengordurado e solvente utilizada foi de $5 \mathrm{~g}$ para $50 \mathrm{~mL}$. Para extração, foi utilizado um balão de fundo chato de $250 \mathrm{~mL}$ com agitador magnético conectado a um condensador. Após contato, o extrato foi filtrado e em seguida foi realizada a análise por cromatografia líquida de alta eficiência (CLAE).

Análise por Cromatografia Líquida de Alta Eficiência

A análise foi realizada em cromatógrafo marca Shimadzu modelo LC 10AD, com detector SPD M10A. A separação cromatográfica foi realizada em coluna $\mathrm{C}_{18}(25 \mathrm{~cm} \times 4 \mathrm{~mm} \times 5 \mathrm{~mm})$, tendo como fase móvel metanol:ácido acético $1 \%(35: 65 \mathrm{v} / \mathrm{v})$, com vazão $0,5 \mathrm{~mL}$ $\mathrm{min}^{-1}$. O detetor utilizado foi o de arranjo de diodos (DAD). A quantificação foi realizada a $313 \mathrm{~nm}$, utilizando-se padronização externa com ácido caféico e de ACG PA (SIGMA). A identificação ocorreu pela 
comparação do espectro da substância com os espectros dos padrões e por comparação dos tempos de retenção dos padrões com os tempos de retenção dos picos das amostras. Todas as análises foram realizadas em duplicata. $\mathrm{O}$ resultado foi expresso em concentração de $\mathrm{ACG}$ no extrato obtido $\left(\mu \mathrm{g} \mathrm{mL}^{-1}\right)$ nessas condições e o rendimento de extração de ACG (\%) foi calculado considerando-se o teor inicial presente no farelo desengordurado.

A análise estatística empregou modelo com três critérios de classificação (solvente, temperatura e tempo de contato) e interações duplas ajustado no software Statgraphics (MANUGISTICS, 1993), bem como os respectivos testes F de Snedecor implícitos na modelagem. Comparações de médias foram realizadas pelo teste T-Student.

\section{RESULTADOS E DISCUSSÃO}

Os resultados da concentração de ACG nos extratos obtidos e o rendimento de extração a partir do farelo estão descritos na tabela 1 . O teor de ACG originalmente presente no farelo desengordurado, obtido a partir da semente da variedade Embrapa F2 BRS descascada, foi de $1,01 \mathrm{~g} 100 \mathrm{~g}^{-1} \mathrm{e}$ foram detetados apenas traços de ácido caféico. Esse resultado se encontra na ampla faixa de variação do teor de ACG no farelo de girassol, que oscila entre $0,06 \%$ até $2,5 \%$ (CANIBE et al., 1999; GONZALEZ-PEREZ et al., 2002).

Os extratos metanólicos apresentaram concentração de ACG variando de 222,57 a 425,72mg $\mathrm{mL}^{-1}$, enquanto nos extratos etanólicos a variação foi de 24,15 a 253,29 mg mL $\mathrm{m}^{-1}$. O rendimento de extração de
ACG para o metanol, em percentual, variou de 22 a $41 \%$ enquanto que para o etanol variou de 2 a $25 \%$. Nestes extratos, o ácido caféico não foi detetado.

Houve diferença significativa $(\mathrm{P}<0,05)$ na extração entre os solventes, tempos de contato e temperaturas, concluindo-se, a partir desses resultados, que o metanol foi mais eficiente que o etanol. Quanto às interações entre os critérios, apenas o efeito tempo X temperatura foi significativo ao nível de 95\% (Tabela 2). $\mathrm{O}$ modelo foi reestruturado admitindo-se apenas essa como interação, que novamente foi significativa $\left(\mathrm{F}_{\text {tempo x temperatura }}=5,25, \mathrm{P}<0,05\right)$.

Analisando separadamente os solventes, para etanol, a interação tempo $\mathrm{X}$ temperatura foi significativa (Tabela 3), o que implicou efeitos significativos de tempo de contato e de temperatura de extração. À medida que a temperatura e o tempo aumentaram, o rendimento de extração de ACG com etanol aumentou significativamente (Tabela 4).

A média obtida para extração com etanol na temperatura de $60^{\circ} \mathrm{C} \mathrm{e} 60$ minutos de contato foi superior a todas as outras combinações $(\mathrm{P}<0,05)$. Para 30 e 60 minutos de contato, houve diferença significativa para as variações de temperatura de 25 a $40^{\circ} \mathrm{C}$; em ambos os casos, o teor de ACG aumentou. No que se refere aos 60min de contato, todas as comparações de médias foram significativas (Tabela 4) e, como exposto, a melhor combinação foi $60^{\circ} \mathrm{C}$ por $60 \mathrm{~min}$.

Para metanol, essa interação não foi significativa e tempo e temperatura foram significativos isoladamente (Tabela 3). Assim, aumentando-se a temperatura aumentou-se significativamente o teor de ACG, e aumentando-se o tempo de extração também

Tabela 1 - Resultados médios de extração do ACG do farelo de girassol desengordurado* para a proporção farelo:solvente de 1:10.

\begin{tabular}{lcccc}
\hline Solvente & Tempo de contato $(\mathrm{min})$ & Temperatura $\left({ }^{\circ} \mathrm{C}\right)$ & $\begin{array}{c}\text { Teor de ACG no extrato } \\
\left(\mu \mathrm{g} \mathrm{mL}^{-1}\right)\end{array}$ & $\begin{array}{c}\text { Rendimento de extração } \\
\text { do ACG do farelo }(\%)\end{array}$ \\
\hline Metanol & 30 & 25 & 222,57 & 22,0 \\
Metanol & 60 & 25 & 279,10 & 27,9 \\
Metanol & 30 & 40 & 245,52 & 23,8 \\
Metanol & 60 & 40 & 409,85 & 40,7 \\
Metanol & 30 & 60 & 399,62 & 39,9 \\
Metanol & 60 & 60 & 425,72 & 40,9 \\
Etanol & 30 & 25 & 24,15 & 2,4 \\
Etanol & 60 & 25 & 24,15 & 2,4 \\
Etanol & 30 & 40 & 27,56 & 2,8 \\
Etanol & 60 & 40 & 150,54 & 14,8 \\
Etanol & 30 & 60 & 163,28 & 16,1 \\
Etanol & 60 & 60 & 253,29 & 25,2 \\
\hline
\end{tabular}

* teor inicial de ACG no farelo de variedade F2 BRS descascada de $1,01 \mathrm{~g} \cdot 100 \mathrm{~g}^{-1}$. 
Tabela 2 - Resultados do modelo a três critérios de classificação (solvente, temperatura e tempo de contato) e interações duplas para o rendimento de extração de ACG do farelo de girassol desengordurado para a proporção farelo:solvente de 1:10.

\begin{tabular}{lccc}
\hline Causa de variação & Graus de liberdade & Soma dos quadrados & Quadrado médio \\
\hline Solvente & 1 & 2884,34 & 2884,34 \\
Tempo & 1 & 336,41 & 336,41 \\
Temperatura & 2 & 1150,36 & 575,18 \\
Solvente x tempo & 1 & 1,03 & 1,03 \\
Solvente x temperatura & 2 & 15,19 & 7,60 \\
Tempo x temperatura & 2 & 150,11 & 75,05 \\
Resíduo & 14 & 200,15 & 14,30 \\
Total & 23 & 4737,61 & 0,07 \\
\hline
\end{tabular}

* significativo $(\mathrm{P}<0,05)$.

aumentou, significativamente, o teor desse ácido. $\mathrm{O}$ rendimento do tratamento a $60^{\circ} \mathrm{C}$ foi significativamente maior do que o obtido nas demais temperaturas. Os melhores resultados foram atingidos utilizando-se metanol a $40^{\circ} \mathrm{C}$ e tempo de contato de 60 minutos; metanol a $60^{\circ} \mathrm{C}$ e 30 minutos; e metanol a $60^{\circ} \mathrm{C}$ e 60 minutos de contato (Figura 1).

Rendimentos superiores aos descritos aqui foram obtidos utilizando-se soluções aquosas, ácidas ou alcalinas, temperaturas altas e maior tempo de contato por SOSULSKI et al. (1973). Entretanto, foram utilizadas inúmeras etapas de extração e alta relação solvente/farelo, fatores que inviabilizam o processo em escala industrial. Tais condições promovem a extração de frações de proteína solúveis e maior desnaturação protéica, em virtude do tratamento térmico para remoção de água do farelo.

A elevação da temperatura causa um efeito marcante, implicando maior remoção dos compostos fenólicos em um tempo menor, mas afetando também a solubilidade do material protéico (DOMÍNGUEZ et al., 1995). Assim, a otimização da temperatura é importante não só com relação ao rendimento de extração de ACG como também em relação aos efeitos na qualidade protéica. Dessa maneira, o emprego de temperaturas mais baixas pode ser mais vantajoso.

A extração dos ácidos ACG e caféico foi também estudada empregando-se solventes hidratados, como metanol $80 \%$, isopropanol $70 \%$ e etanol 95\%, com resultados de remoção de 100, 88 e 24\%, respectivamente (GONZALEZ-PEREZ et al., 2002). Entretanto, o tempo de extração foi de 4 h e a relação farelo:solvente foi 1:20, parâmetros de processo pouco vantajosos, particularmente em escala industrial. Devese considerar ainda a energia necessária para a recuperação do solvente e as alterações que podem ocorrer na proteína.

O uso de isopropanol anidro também foi descrito, com rendimento de extração de $98 \%$ (SEN \&

Tabela 3 - Resultados do modelo a três critérios de classificação (solvente, temperatura e tempo de contato) e uma interação dupla para o rendimento de extração de ACG do farelo de girassol desengordurado segundo solventes utilizados em cada extração.

\begin{tabular}{|c|c|c|c|c|c|c|}
\hline Solvente & & Causa de variação & Graus de liberdade & Soma dos quadrados & Quadrado médio & $\mathrm{F}$ \\
\hline \multirow[t]{5}{*}{ Etanol } & Coef. ajust. & Tempo & 1 & 150,06 & 150,06 & $49,62 *$ \\
\hline & 0,9806 & Temperatura & 2 & 689,13 & 344,57 & $113,94^{*}$ \\
\hline & Média ajust. & Tempo x temperatura & 2 & 78,12 & 39,06 & $12,92 *$ \\
\hline & 10,60625 & Resíduo & 6 & 18,14 & 3,02 & \\
\hline & & Total & 11 & 935,45 & & \\
\hline \multirow[t]{5}{*}{ Metanol } & Coef. ajust. & Tempo & 1 & 187,39 & 187,39 & $9,33^{*}$ \\
\hline & 0,8687 & Temperatura & 2 & 476,43 & 238,21 & $11,86^{*}$ \\
\hline & Média ajust. & Tempo x temperatura & 2 & 133,51 & 66,76 & 3,32 \\
\hline & 32,53167 & Resíduo & 6 & 18,14 & 3,02 & \\
\hline & & Total & 11 & 935,45 & & \\
\hline
\end{tabular}

* significativo $(\mathrm{P}<0,05)$. 
Tabela 4 - Resultados de testes de diferenças de médias 2 a 2 para o rendimento de extração de ACG de farelo de girassol utilizando-se etanol.

\begin{tabular}{|c|c|c|c|c|c|c|c|}
\hline \multirow{3}{*}{ Tempos de contato } & \multirow{3}{*}{ Temp. } & \multicolumn{6}{|c|}{-Tempos de contato---1- } \\
\hline & & \multicolumn{3}{|c|}{------------------30min------------------ } & \multicolumn{3}{|c|}{------------------60min------------------ } \\
\hline & & $25^{\circ} \mathrm{C}$ & $40^{\circ} \mathrm{C}$ & $60^{\circ} \mathrm{C}$ & $25^{\circ} \mathrm{C}$ & $40^{\circ} \mathrm{C}$ & $60^{\circ} \mathrm{C}$ \\
\hline \multirow[t]{3}{*}{$30 \mathrm{~min}$} & $25^{\circ} \mathrm{C}$ & - & & $*$ & & $*$ & $*$ \\
\hline & $40^{\circ} \mathrm{C}$ & & - & $*$ & & $*$ & $*$ \\
\hline & $60^{\circ} \mathrm{C}$ & $*$ & $*$ & - & $*$ & & $*$ \\
\hline \multirow[t]{3}{*}{$60 \mathrm{~min}$} & $25^{\circ} \mathrm{C}$ & & & $*$ & - & $*$ & $*$ \\
\hline & $40^{\circ} \mathrm{C}$ & * & $*$ & & $*$ & - & $*$ \\
\hline & $60^{\circ} \mathrm{C}$ & $*$ & $*$ & $*$ & $*$ & $*$ & - \\
\hline
\end{tabular}

* significativo $(\mathrm{P}<0,05)$, pelo teste $\mathrm{T}-$ Student.

BHATTACHARYYA, 2000). Também neste caso, um tempo de extração mais longo e maiores temperaturas para a remoção do isopropanol foram necessários, condições deletérias à qualidade protéica do farelo. As vantagens da utilização de solventes anidros estão associadas a um menor consumo de energia para a recuperação do ACG do extrato e ao uso de temperaturas mais baixas para a remoção do solvente residual no farelo desengordurado.

O metanol não é um solvente grau alimentício, porém os extratos teriam vasta aplicação na oleoquímica para promover o aumento da estabilidade oxidativa de óleos industriais ou de biodiesel, em virtude de sua atividade antioxidante. Já os extratos etanólicos, embora obtidos com menor rendimento, poderiam ser utilizados como antioxidantes em óleos vegetais, com a vantagem da reincorporação do ACG presente originalmente no girassol, mas que é perdido durante o processo de refino do óleo.

\section{CONCLUSÃO}

A extração de ACG do farelo desengordurado de girassol foi significativamente mais eficiente com metanol que com etanol anidro e o aumento do tempo de contato e da temperatura de extração promoveram aumento significativo no rendimento de ACG. Após a extração com etanol do ACG, há possibilidade do uso do farelo para a alimentação. Já os extratos metanólicos teriam vasta aplicação na oleoquímica.

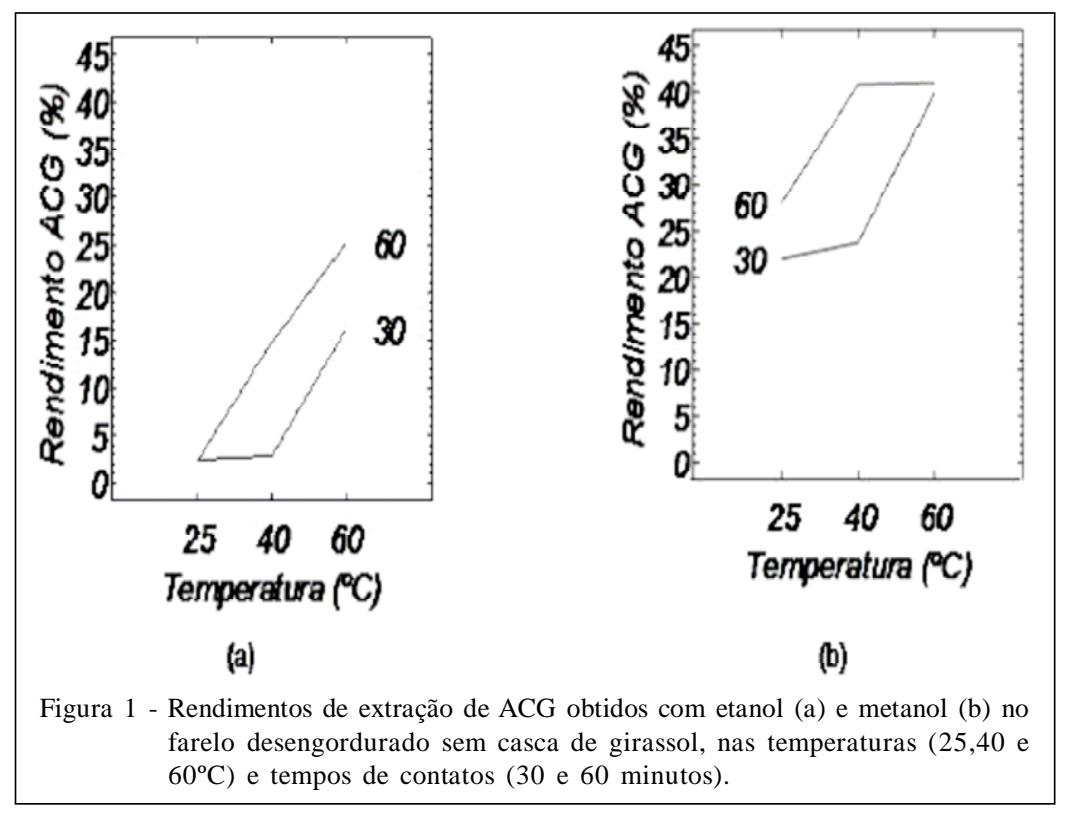

Ciência Rural, v.41, n.4, abr, 2011. 


\section{REFERÊNCIAS}

ALLAM, S.S.M.; BASSIUNY, A.M.M. Chlorogenic acid, efficiency and safety aspects as antioxidant. La Rivista Italiana delle Sostanze Grasse, Milão, v.78, p.257-265, 2002.

AOCS - AMERICAN OIL CHEMISTS' SOCIETY. Official methods and recommended practices of the american oil chemists' society. Champaign, IL., 2009. 1200p.

BERNARDINI, E. Oilseeds, oils and fats. Rome : B. E. Oil Publishing House, 1983. V.1, 600 p.

CANIBE, N. et al. Chemical composition, digestibility and protein quality of 12 sunflower (Helianthus annuus L) cultivars. Journal of the Science of Food and Agriculture, London, v.79, n.13, p.1775-1782, 1999. Disponível em: <http:// onlinelibrary.wiley.com/doi/10.1002/\%28SICI\%2910970010\%28199910\%2979:13\%3C\%3E1.0.CO;2-B/issuetoc>. Acesso em: 03 dez. 2010. doi: 10.1002/(SICI)10970010(199910)79:13<1783::AID-JSFA392>3.0.CO;2-6.

DE LEONARDIS, A. et al. Biodegradation in vivo and in vitro of chlorogenic acid by a sunflower-seedling (Helianthus annuus) like-polyphenoloxidase enzyme. European Food Research and Technology, Berlin, v.223, p.295-301, 2006. Disponível em: <http://www.springerlink.com/content/1438-2377/223/3/>. Acesso em: 03 dez. 2010. doi: 10.1007/ s00217-005-0209-5.

DE MARIA, C.A.B.; MOREIRA, R.F.A. Métodos para análise de ácido clorogênico. Química Nova, São Paulo, v.27, n.4, p.586592, 2004. Disponível em: <http://quimicanova.sbq.org.br/qn/ qnol/2004/vol27n4/index.htm>. Acesso em: 03 dez. 2010.

DOMÍNGUEZ, H. et al. Aqueous processing of sunflower kernels with enzymatic technology. Food Chemistry, London, v.53, p.427-434, 1995. Disponível em: <http://www.sciencedirect.com/ science?_ob=PublicationURL\&_tockey $=\% 23$ TOC $\% 235037 \% 2319$ 95\%23999469995\%23181400\%23FLP\%23\&_cdi=5037\&_p ubType $=J \& \_a u t h=y \& \_a c c t=C 000012878 \& \_v e r s i o n=1 \& \_u r l V e r s i o n=$ 0\&_userid=7430124\&md5=f6d79a5b0b5a8a9b7970bd5a31b56067>. Acesso em: $06 \mathrm{dez} .2010$

FARAG, M.D.E.H. Effect of radiation and other processing methods on protein quality of sunflower meal. Journal of the Science of Food and Agriculture, London, v.79, p. 15651570, 1999. Disponível em: <http://onlinelibrary.wiley.com/ d o i / $10.1002 / \% 28$ S I C I \% 29101097 0010\%28199909\%2979:12\%3C\%3E1.0.CO;2-6/issuetoc>. Acesso em: 06 dez. 2010. doi: 10.1002/(SICI)10970010(199909)79:12<1565::AID-JSFA393>3.0.CO;2-N.
FERRARI, R.V. O girassol está invadindo. Bunge no campo, São Paulo, v.1 n.5, p.2-3, 2004.

FURLAN, A.C. et al. Utilização do farelo de girassol na alimentação de frangos de corte. Revista Brasileira de Zootecnia, Viçosa, v.30, n.1, p.158-164, 2001. Disponível em: 〈http://www.scielo.br/pdf/rbz/v30n1/5448.pdf>. Acesso em: 06 dez. 2010.

GONZALEZ-PEREZ, S. et al. Isolation and characterization of undenatured chlorogenic acid free sunflower (Helianthus annuus) proteins. Journal of Agricultural and Food Chemistry, Easton, v.50, v.6, p.1713-1719, 2002. Disponível em: 〈http://pubs.acs.org/ doi/pdf/10.1021/jf011245d〉. Acesso em: 06 dez. 2010. doi: 10.1021/jf011245d.

GROMPONE, M.A. Sunflower oil. In: SHAHIDI, F. Bailey's industrial oil \& fat products. 6.ed. Hoboken, NJ: John Wiley \& Sons, 2005. V.2.

MANUGISTICS. Statgraphics reference manual. Rockville: Manugistics, 1993. 642p.

MARTINEZ, E.; DUVNJAK, Z. Enzymatic degradation of chlorogenic acid using a polyphenol oxidase preparation from the white-rot fungus Trametes versicolor ATCC 42530. Process Biochemistry, London, v.41, p.1835-1841, 2006. Disponível em: <http://www.sciencedirect.com/ science?_ob=PublicationURL\&_tockey $=\% 23$ TOC $\% 235278 \% 232$ $006 \% 23999589991 \% 23623887 \% 23$ FLA $\% 23 \&$ \& cdi $=5278 \&$ _pubType=J\&_auth=y\&_acct=C000012878\&_version=1\&_urlVersion $=0$ \& _userid $=7430124 \& \mathrm{md} 5=\mathrm{e} 66 \mathrm{c} 8$ bada49eb9cf972000d57ecafa67 $>$. Acesso em: 06 dez. 2010. doi:10.1016/j.procbio.2006.03.036.

PEDROSA, M.M. et al. Determination of caffeic and chlorogenic acids and their derivatives in different sunflower seeds. Journal of the Science of Food and Agriculture, London, v.80, n.4, p.459-464, 2000. Disponível em: <http://onlinelibrary.wiley.com/ doi/10.1002/(SICI)1097-0010(200003)80:4\%3C\%3E1.0.CO;2U/issuetoc>. Acesso em: 06 dez. 2010. doi: 10.1002/ (SICI)10970010(200003)80:4<459::AID-JSFA549>3.0.CO;2-O

SEN, M.; BHATTACHARYYA, D.K. Nutritional quality of sunflower seed protein fraction extracted with isopropanol. Plant Foods for Human Nutrition, Dordrecht, v.55, n.3, p.265278, 2000. Disponível em: <http://www.springerlink.com/ content/0921-9668/55/3/>. Acesso em: 06 dez. 2010.

SOSULSKI, F.W. et al. Continuous diffusion of chlorogenic acid from sunflower kernels. Journal of Food Science, Chicago, v.38, p.468-470, 1973. Disponível em: <http:// onlinelibrary.wiley.com/doi/10.1111/jfds.1973.38.issue-3/ issuetoc>. Acesso em: 06 dez. 2010. doi: 10.1111/j.13652621.1973.tb01456.x. 